Paper ID \#18872

\title{
Comparison of Two Survey Instruments for the Assessment of Entrepreneurial Mindset
}

\section{Dr. Thomas P. James P.E., Rose-Hulman Institute of Technology}

Tom James is presently a Professor of Entrepreneurship at Rose-Hulman Institute of Technology. His major interests are new product development and global business ventures. He currently teaches courses in accounting, finance, and entrepreneurial studies. In addition to teaching, Dr. James directs the ESCALATE program, a living-learning community focused on integrating entrepreneurship and technical disciplines. He received his $\mathrm{PhD}$ in Mechanical Engineering and an Executive MBA from Marquette University. He is a Fellow of the American Society of Mechanical Engineers and is a registered Professional Engineer (PE). Dr. James is also an avid inventor with over two dozen patents and he has several publications in peer reviewed journals related to his research in biomechanical systems. Prior to joining academia, he worked for over a decade in the consumer products industry, most recently as Senior Vice President of Global Engineering at Techtronic Industries, headquartered in Hong Kong, where he lived with his family for several years.

\section{Dr. Craig G. Downing, Rose-Hulman Institute of Technology}

Craig G. Downing is Department Head and Associate Professor of Engineering Management at RoseHulman Institute of Technology. His teaching responsibilities are focused on delivering graduate-level instruction related to Operations and Quality Systems. His interests are rooted in Academic-Industrial partnerships, Process Improvement, and Action Research in Engineering Management. Further, serves as one of the champions for leading the campus entrepreneurial initiatives. He is a certified Lean Six Sigma Master Black Belt.

\section{Dr. Diane Evans, Rose-Hulman Institute of Technology}

Dr. Diane Evans was previously a professor in the mathematics department at Rose-Hulman Institute of Technology from 2001 to 2016, and she joined the engineering management department in 2016. She received her BS and MA degrees in mathematics at The Ohio State University and her MS and PhD in operations research and applied science from the College of William and Mary. Diane received her Black Belt in Six Sigma in 2011 from Purdue's Technical Assistance Program. Her current research and teaching interests are in probability, statistics, quality control, and Six Sigma. She has published journal articles in the areas of probability, statistics, statistics education, quality control, and Six Sigma, and has published a book in computational probability. Diane won Rose-Hulman's Dean's Outstanding Teacher Award in 2007, was named in Princeton Review's 300 Best Professors in America in 2012, and was selected as one of Microsoft's 365 "Heroes in Education" in 2012. In 2014, Diane was nominated for U.S. Professor of the Year and Indiana's Women \& Hi Tech's "Outstanding Educator in STEM." In Winter Quarter 2015, Diane spent her sabbatical working for Minitab statistical software company producing educational materials for new statistics instructors. These materials are available at: https://www.minitab.com/enus/academic/teaching-resources/. 


\title{
Comparison of Two Survey Instruments for the Assessment of Entrepreneurial Mindset
}

\begin{abstract}
Conversations regarding outcome assessment naturally precipitate as the entrepreneurship curriculum matures from certificates and minors to undergraduate and graduate degree programs. In general, the assessment conversation begins with a discussion and comparison of entrepreneurial skills versus entrepreneurial mindset. The assessment of skills, such as the ability to discern information from a balance sheet or the ability to create a robust business model, is a more straightforward endeavor than documenting a temporal change in mindset. Questions such as, "Have we changed how a student thinks about risk?" or "Have we affected a student's perception on the feasibility of becoming an entrepreneur?" are more difficult to answer than skills assessment from a metrics-based perspective. However, progress is evident in the development of tools to document entrepreneurial mindset and hence through longitudinal studies measure the potential impact of curriculum and co-curricular activities on changing mindset. This paper compares and contrasts two relatively new tools for assessment of entrepreneurial mindset: (1) Entrepreneurial Mindset Profile (EMP), which has origins back to 2010 at Eckerd College in St. Petersburg, Florida, and (2) Entrepreneurial Profile 10 Index (EP10), by Gallup with underpinnings in 2009. Both are web-based surveys.

For this research, 70 undergraduate students majoring in math, science, or engineering completed both instruments. Forty students were enrolled in an Introduction to Entrepreneurship course, with the remainder enrolled in an Introduction to Engineering Management course. The instruments are first compared based on the authors' perspective of practical mechanics, such as ease of administration, the time required for completion, instructions to students, formatting of questions, and access to results to name a few. Additionally, the research presents a correlation study of results for the same students taking both instruments. In addition, students who participated in the research were surveyed to gain insight into their experience when completing the instruments, such as time allotted, clarity of questions, and understanding of results. Finally, students were asked to express their judgment on the perceived value of these instruments to provide useful knowledge about their entrepreneurial mindset.

The results of this research are particularly relevant to faculty and administration interested in measuring changes in entrepreneurial mindset by adopting a commercially available assessment instrument or by developing an in-house instrument. Faculty interested in the concept of the entrepreneurial mindset, whether they use the EMP, EP10 or some other psychometric instrument as a classroom activity or assessment are a secondary audience for results presented herein.
\end{abstract}




\section{Introduction}

In the book, The Entrepreneurial Society, by David Audretsch, he makes a persuasive argument that our future economic growth will depend on the upcoming generation as they fully engage in global entrepreneurship in pursuit of purposeful and satisfying ventures that align with their values $^{1}$. From an educational perspective, our institutions are clearly moving in rapid progression to meet a perceived rising interest in entrepreneurship by creating new degree programs and co-curricular elements, to include co-working spaces and incubators. It is estimated that in 1985 there were about 250 entrepreneurship courses offered on college campuses and by 2008 there were over 5,000 courses ${ }^{2}$. However, there is an alternative argument, made by the founder of Venture for America, Andrew Yang, in his book Smart People Should Build Things ${ }^{3}$. He makes the observation that graduates from the most prestigious universities, mainly the Ivy League, take jobs at very established companies or enter very traditional fields, as opposed to starting companies. Consider Harvard, for example, where graduates take jobs in finance (10-17\%), consulting (7-11\%), law (12-17\%), and medicine (12$16 \%)$, or go on to graduate school (8-9\%) $)^{3}$. If our best and brightest inspire to attend elite schools and upon graduation take jobs, rather than create businesses, one may ask if our instructional approach to teaching entrepreneurship is changing mindsets. Upon reflection, we must ask ourselves, "Does an educational experience infused with entrepreneurship create more entrepreneurial minded people?", and more specifically, "How can we assess if a change in mindset is occurring on our campus?"

There are two macroscale approaches to conducting research on the subject of entrepreneurship, with one focusing on the impact of entrepreneurship in the economy and how ventures are started, organized, and managed, while the other is focused on the entrepreneur themselves, through an investigation of attributes like motivation, inherent and learned behavior, and skills. In our contemporary society, the term entrepreneurial mindset has evolved to represent an amalgamation of entrepreneurial skills, motivations, and thought processes. The entrepreneurial mindset appears in many contexts, including the discussion of entrepreneurial intent ${ }^{4}$, the practice of business ${ }^{5}$, and the educational process, especially as it pertains to engineering ${ }^{6-8}$. It is here, on the mindset of the person, rather than on the outcome of their action, that we chose to pursue our assessment of entrepreneurship education. Our focus is more on the assessment of learning than on the cataloging of activity, i.e. number of startups, amount of funding raised, number of students taking entrepreneurship courses, etc.

In an effort to assess the entrepreneurial mindset of our students, the authors began researching current psychometric tools to assist in this charge. The two assessment instruments selected for the project were the Entrepreneurial Profile (EP10), which was recently rebranded as the Builder Profile (BP10), and the Entrepreneurial Mindset Profile (EMP). Both surveys are facilitated electronically (web-based) by Gallup and Eckerd College, respectively. Our motivation is to assess if entrepreneurship programs at our institution, both didactic and co-curricular, deliver on the hypothesis that education can influence entrepreneurial mindset. For context, our educational mission is to graduate the best math, science, and engineering students, so our campus is unique 
in that we do not matriculate those interested solely in the liberal arts. Hence, the research presented here does not reflect all educational disciplines.

There is some temptation to identify an entrepreneur with a test of sorts, or at least capture the likelihood of entrepreneurial intention in a quantitative manner. If you search "Test for Entrepreneurship" on the internet, the first page of the search will reveal several tests that you can take (pay for) to see if you have the right stuff. However, the measurement of human traits and motivations and correlation between those metrics and entrepreneurial intent can be a perilous journey, meaning it is difficult to construct a broadly applicable instrument that shows correlation with statistical significance. Nevertheless, we are enticed by instruments that tell us something about ourselves, if for no other purpose than to obtain knowledge through selfreflection, thereby influencing our future learning and growth. For example, for those reading this paper, what percentage has taken the Myers-Briggs Type Indicator $₫$ ? According to the Myers-Briggs Company ${ }^{9}$, the personality assessment tool first appeared in 1942 and is taken annually by over 1.5 million people, "including to employees of most Fortune 500 companies."

Why would companies pay to have their employees take a personality test? Would a founder's score on an entrepreneurial mindset test influence investors in famed Silicon Valley? Is there a future where students take an entrepreneurial mindset assessment as part of the admissions process into an entrepreneurship program? These are important questions because they help us to focus our attention on our motivations for undergoing this pilot study, where we compare two instruments designed to assess entrepreneurial mindedness. To be clear, we are not trying to find a test to court future entrepreneurs. Also, we are not trying to pick one instrument over the other. In fact, we are not subscribing to the belief that these instruments actually measure entrepreneurial mindset.

Our intention in this paper is to introduce two instruments that have recently emerged in this field of study and to investigate potential correlation between their categorical measurements. For example, both instruments attempt an evaluation of a person's tolerance for Risk. For this category, we asked, "If the same group of students complete both assessments, will there be correlation between their scores related to Risk tolerance?" In addition to Risk, there was overlap between the two instruments on the categories of Independence, Confidence, and Persistence. Finally, we wanted to investigate costs related to taking these types of assessments, format of questions and results, time to complete the assessment, and direct feedback from students on their perception of usefulness.

\section{Comparison of EMP and EP10}

In this section, background is provided on the Development and Validation of both the Entrepreneurial Mindset Profile (EMP) and the Entrepreneurial Profile (EP10), as well as a comparison of their Format and Cost. With regard to format, we discuss the assessment and subsequent presentation of results. Information on development and validation of the EMP is taken from a journal publication, Developing a New Measure of Entrepreneurial Mindset: Reliability, Validity, and Implications for Practitioners ${ }^{10}$, while information for the EP10 was 
ascertained from the Entrepreneurial Profile 10 Methodology Report published on Gallup's Strengthsfinder ${ }^{\circledR}$ website ${ }^{11}$.

\subsection{Development}

There appears to be three steps to developing these types of personality instruments: (i) determine the correct set of traits and skills indicative of the desired behavior, (ii) create statements or items where an affirmative response supports evidence of a given trait or skill, and (iii) validate the instrument by eliciting participation from the target and alternative audience. For now, we discuss the first two steps in this process, while validation appears in the next section.

In the first step, the journey to develop the EMP and EP10 have many parallels, but there are some notable differences. In both instruments, developers claim that personality traits help explain entrepreneurial behavior as evidenced in the historical literature. Each then embarks on an extensive survey of said literature, summarizing research in this vast field, ultimately proposing a multitude of traits and subsequent correlation to entrepreneurial behavior.

Considering differences in their approaches, the EMP clearly states a focus on entrepreneurial mindset during development of the instrument and further, makes a clear distinction and intentional split between traits and skills. Paraphrasing their language, a person's skills can be nudged with education, but traits are more stubborn and inherent. Ultimately, through two rounds of correlation studies, the EMP settles on seven traits and seven skills to capture entrepreneurial mindset, Table 1.

Table 1: EMP categories of traits and skills

\begin{tabular}{ll}
\hline \hline Traits & Skills \\
\hline Independence & Future Focus \\
Preference for Limited & Idea Generation \\
Structure & \\
Nonconformity & Execution \\
Risk Acceptance & Self-Confidence \\
Action Orientation & Optimism \\
Passion & Persistence \\
Need to Achieve & Interpersonal Sensitivity \\
\hline \hline
\end{tabular}

Meanwhile, the EP10 Methodology Report consistently refers to entrepreneurial talent as opposed to mindset, with talent described as "...consistent patterns of thought, feeling and behavior of successful entrepreneurs." The EP10 purports to focus on innate traits, leading to a list of ten talents that drive entrepreneurial behavior, shown in the first column of Table 2 . The EP10 does not claim to pursue an assessment of skills, but this may be semantics because there is overlap between EMP traits/skills and EP10 talents as shown in the second column of Table 2. 
Table 2: EP10 categories for talents, with an equivalent EMP trait/skill where applicable

\begin{tabular}{lc}
\hline \hline EP10 Talents & EMP Traits / Skills \\
\hline Confidence & Self-Confidence (skill) \\
Risk (Risk-Taker)* & Risk Acceptance (trait) \\
Disruptor** & $-----* * *$ \\
Selling (Promoter) & ---- \\
Profitability (Business Focus) & ----- \\
Knowledge & ---- \\
Independence & Independence (trait) \\
Determination & Persistence (skill) \\
Delegator & ----- \\
Relationship & ----- \\
\hline \hline
\end{tabular}

* The terms in parentheses appeared in the EP10 Methodology Report, but were replaced with the non-parenthetical words in the web-based instrument.

**The category "Disruptor" appeared in the web version, whereas the category "Creative Thinker" appeared in the report.

***The dashes indicate there is no apparent equivalent between the EP10 talents and EMP traits/skills.

Obviously, there is some debate related to the categorization of personality attributes as either talents, traits, or skills. For our purpose, however, we focused on investigating correlation between the four matching pairs of EP10 talents and EMP traits/skills, Table 2. In three of the four descriptors, the language is very consistent (Confidence/Self-Confidence; Risk/Risk Acceptance; Independence/Independence), whereas in the fourth instance we assumed Determination and Persistence were synonymous.

In the development of these instruments, both teams pursued pilot studies, followed by a down selection process to arrive at final categories to capture entrepreneurial behavior and items that were positively associated with finalist categories. However, in development of the EP10, qualitative research was split between two groups, successful entrepreneurs, and non-successful entrepreneurs, as they tried to ferret out differences in talents. In comparison, during development of the EMP, researchers differentiated between entrepreneurs and nonentrepreneurs. The non-entrepreneurs were managers, meaning they self-identified as being nonentrepreneurial and they had a management role in a business. It appears the EMP team approached the research from a more purist view of psychology, while the EP10 team chose a blended approach between psychology and business, leading to EP10 talent categories like selling, profitability, and delegator. In fact, the goal of the EP10, stated succinctly in the Methodology Report, is "....to identify entrepreneurs who are likely to significantly grow their businesses."

\subsection{Validation and Reliability}

Gallup used a web-based survey to find 1,188 primary business owners to participate in EP10 validation. From this pool of entrepreneurs, only 905 qualified as "opportunity driven" as opposed to "necessity driven," with necessity driven meaning they responded that starting a 
business was necessary because there were no jobs in their area. The instrument was not developed to distinguish entrepreneurs from non-entrepreneurs, but rather to indicate the likelihood the entrepreneur will seek high growth opportunities. There was no information given on the types of businesses represented by the entrepreneurs. Results from this pilot of opportunity-driven entrepreneurs were used to evaluate individual items and the instrument as a whole. According to Gallup, analysis supported 89 items that best indicated the talents necessary to grow a business, where talent explained $5 \%$ of the variance in entrepreneurial performance after controlling for age, gender, size of company, and previous entrepreneurial experience. An index with a composite score of zero to 100 was then developed, with a higher score indicating the potential to have more success growing a business. From the standpoint of reliability, Cronbach's alpha coefficient for the EP10 assessment was 0.90 .

After several pilot studies to arrive at a list of 72 Likert-type scale items, with 5 or 6 items for each of the 14 traits/skills, researchers from Eckerd College conducted two studies for validation of the final EMP instrument. The validation studies consisted of 389 entrepreneurs and 397 managers from a diverse group of industries, including manufacturing, finance, hospitality, energy, and technology. In addition, they conducted a study with college students, where 183 self-identified as being entrepreneurs and 175 as not being entrepreneurs. For the sample of entrepreneurs and managers, statistical analysis supported 13 of the 14 traits/skills as being significant, with only Need to Achieve being indistinguishable ( $\mathrm{p}<0.01)$. In all categories, except Interpersonal Sensitivity, the entrepreneurs scored higher than the managers did. For the student sample, 11 of the 14 traits/skills demonstrated significance for the self-identified groups (Entrepreneur: Yes or No). The remaining traits/skills for the student population, namely Nonconformity, Action Orientation, and Future Focus were not statistically significant ( $\mathrm{p}<$ 0.01). From the standpoint of reliability, Cronbach's alpha coefficient for the EMP assessment was 0.77 .

Demographically, the validation pool for both the EP10 and EMP lacks significant diversity. For example, when looking at race, the EP10 sample was 91\% white and the EMP sample was $88 \%$ white. Considering gender, participants in the EP10 and EMP samples were 60\% male and 59\% male, respectively. For the EMP, the mean age was 40.7 years old, while $84 \%$ of the EP10 respondents where greater than 40 years old. Essentially, the validation pool for both instruments was older white males, which is not indicative of the more diverse and younger age of students in most college settings. Specific to EMP validation, researchers included a sample of college students ( 67 men; 60 women) to see if the instrument accurately identified entrepreneurs from non-entrepreneurs based on student self-selection. However, the mean age among the college participants was 43.4 years old and they were $80 \%$ white.

\subsection{Format of Results}

There are significant differences between the EMP and EP10 in presentation of results to participants. The EP10 report does not contain a quantitative review of results. Rather, the participant receives a report with the talents listed from 1 to 10 , where a 1 represents the 
strongest talent and a 10 represents the weakest talent. On the cover page of a report, the top four talents are listed, in addition to one of three styles based on a grouping of talents, Table 3.

\begin{tabular}{cc} 
Table 3: Grouping of talents into three groups called Styles & \\
\hline \hline Style & Talent \\
\hline & Delegator \\
Activation & Determination \\
& Independence \\
& Risk \\
\hline \multirow{2}{*}{ Relational } & Disruptor \\
& Knowledge \\
& Relationship \\
\hline \multirow{2}{*}{ Strategic } & Confidence \\
& Profitability \\
& Selling \\
\hline \hline
\end{tabular}

The report recommends a style based on a ranking of talents. For example, if after taking the EP10, two of the top talents identified are Confidence and Profitability, the participant will be categorized as having a Strategic style. Each style category includes two summary paragraphs, with one describing "Your Talent" and the other noting "Using Your Talent." Table 4 contains an example of the text related to the Strategic style category.

Table 4: Description provided for Strategic style ${ }^{11}$

\begin{tabular}{ll}
\hline \hline Style & \multicolumn{1}{c}{ Description } \\
\hline & Your Talent: You have an extremely clear growth strategy. \\
& $\begin{array}{l}\text { You tend to take a long-term approach and a big picture } \\
\text { perspective. You focus on goals and you measure success by } \\
\text { profitability. }\end{array}$ \\
& $\begin{array}{l}\text { Using Your Talent: Aggressively pursue growth strategies. } \\
\text { Energize customers and employees by painting a vision for } \\
\text { the future. Be the voice and face of your organization or } \\
\text { activity. }\end{array}$ \\
\hline \hline
\end{tabular}

From an instructional perspective, each student receives the personalized EP10 report, but a summary (group) report for the entire class is not available. In addition, participants cannot see the individual items and their associated response scores.

While results from the EP10 are presented qualitatively, the EMP report is at the other end of the spectrum, reporting quantitative data in both tabular and graphical format. The data associated with each item is provided in a table with a score from 1 to 5 , where a 1 represents the response "Does not describe me well" and a 5 represents the response "Describes me well" to any particular item. A group report is available to the faculty member to share with the class. An example data set and related items for Persistence is shown in Table 5. This data is from a group report that consisted of 41 first year students taking an introduction to entrepreneurship course at 
our institution. When looking at the individual items, some results are negative because good practice dictates that not all items (shown in italics, Table 5) should be presented in the affirmative.

Table 5: Raw data from a Group Report for the EMP skill "Persistence"

\begin{tabular}{|c|c|c|c|c|}
\hline Persistence & $\begin{array}{l}\text { Group } \\
\text { Range }\end{array}$ & $\begin{array}{l}\text { Group } \\
\text { Score }\end{array}$ & $\begin{array}{l}\text { Corp. } \\
\text { Norm } \\
\text { Score }\end{array}$ & $\begin{array}{l}\text { Entr. } \\
\text { Norm } \\
\text { Score }\end{array}$ \\
\hline Overall Scale Score & & 4.40 & $4.25^{*}$ & $4.50^{*}$ \\
\hline I am persistent when pursuing a goal. & $3-5$ & 4.46 & 4.29 & 4.47 \\
\hline When faced with a problem, I keep working toward a solution. & $3-5$ & 4.46 & 4.40 & 4.60 \\
\hline I do not give up easily. & $3-5$ & 4.73 & 4.28 & 4.55 \\
\hline I get discouraged pretty easily. & $(1-4)$ & $(2.05)$ & $(1.86)$ & $(1.65)$ \\
\hline When I encounter obstacles along my path, I find a way to overcome them. & $2-5$ & 4.41 & 4.16 & 4.54 \\
\hline
\end{tabular}

Tabular data is used to calculate an average score for each of the 14 scales. The tabular response data is split into two graphs, one for the seven traits and one for the seven skills. Each graph contains two baselines, which represent the average responses from the two validation groups, namely entrepreneurs and managers. An example graph from a group report for skills is shown in Figure 1.

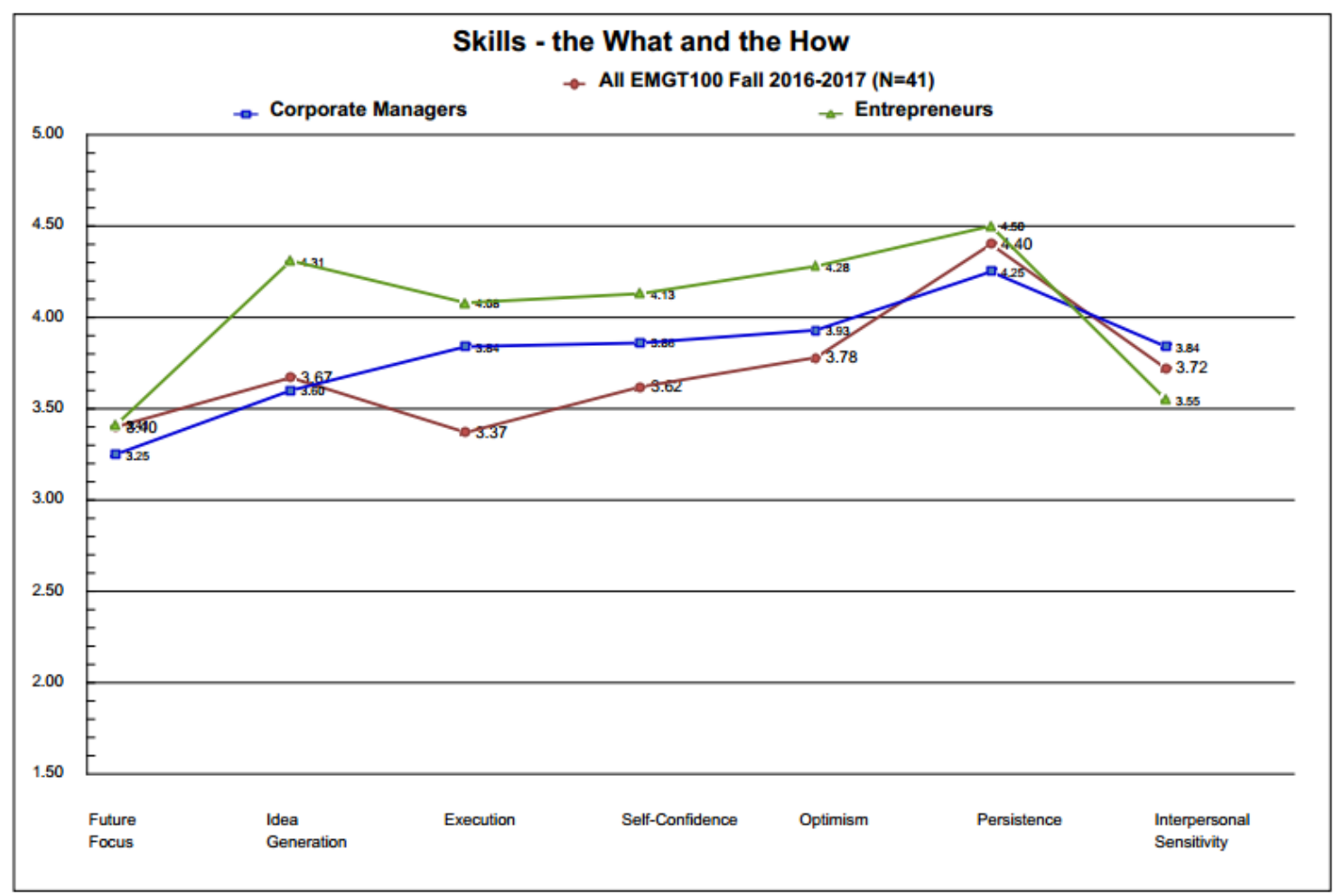

Figure 1: A graph from the EMP group report showing the seven scales associated with Skills. Participants $(\mathrm{N}=41)$ were first-year students taking an introduction to entrepreneurship course. The brown line (circles) represents the averages determined from student responses. For reference, the green line (triangles) represents baseline validation data for "entrepreneurs" and the blue line (squares) represents baseline validation data for "managers," i.e. non-entrepreneurs. Here, the students scored relatively low on Execution, Self-Confidence, and Optimism. 


\subsection{Cost, Time to Complete, and Product Support}

The retail price for the EP10 is $\$ 12$ per participant. The EP10 takes approximately 30 minutes to complete. The report is emailed to students immediately upon completion of the instrument.

The EMP has a two-tier system for pricing. The retail price is $\$ 45$ for participants outside of academia, but for students the EMP cost is $\$ 25$. With regard to group reports, the cost is $\$ 250$ outside of academia and $\$ 100$ for instructors that use the EMP in class. The EMP takes approximately 30 minutes to complete. The report is emailed to students immediately upon completion of the instrument. The instructor creates a group of the applicable participants through the EMP website and follows a link to the group report.

From a product support standpoint, there is no apparent method (email or phone number) to contact someone from Gallup by looking at their EP10 website. The EMP website contains a phone number and an email address. We called the phone number to get the aforementioned pricing information for the educational discount and the group report pricing because they were not available on the website.

\section{Methodology}

To become familiar with the instruments, one of the authors attended a two-day workshop at Eckerd College, FL, to become a certified practitioner for the EMP. Meanwhile, a different author attended a three-day training workshop related to becoming a certified EP10 coach and a five-day training workshop to be a certified Strengthsfinder coach. Gallup, Inc. administers both training programs and assessments.

During the fall quarter of the 2016-17 academic year, the authors used a sample of convenience to pilot utilization of the instruments. For the pilot, both the EP10 and EMP were given to 70 undergraduate students majoring in math, science, or engineering. Forty-two participants were first-year students enrolled in an Introduction to Entrepreneurship course (EMGT100), with the remainder enrolled in an Introduction to Engineering Management course (EMGT330), which consisted primarily of seniors and graduate students. Students in the EMGT100 course were provided in-class time to complete the survey as an element of the entrepreneurial lectures. Alternatively, students in EMGT330 completed the surveys as a homework assignment related to curiosity and self-awareness. Students in EMGT100 have proactively communicated their entrepreneurial desires, while students in EMGT330 are exploring career paths in leadership and management, in or related to their technical discipline.

Tactically, each student was provided an email with an access code and instructions for taking the assessments. Each administering agency provided the content of the email. Once students received the access codes, the process flowed smoothly (i.e., no technical problems). However, there were a couple of instances in which students did not complete both surveys. After the data collection, students were queried to gain insight into their experience when completing the surveys, such as time allotted, clarity of questions, and understanding of results. Finally, 
students were asked to express their judgment on the perceived value of these instruments to provide useful knowledge about their entrepreneurial mindset.

The first step in statistical analysis was to hand transfer student assessment results from the two instruments into MS Excel®. Next, the spreadsheet data was imported into Minitab 17® where four scatter plots were created for each of the four paired categories shown in Table 2. For each scatter plot, EP10 data was distributed along the abscissa, while EMP data was plotted on the corresponding ordinate axis. Correlation between the EMP and EP10 categories was determined by Spearman's correlation coefficient, with statistical significance set at $\mathrm{p}<0.05$.

All aspects of this pilot project were reviewed and approved by the Institutional Review Board (IRB) for research involving human subjects. Additionally, students gave signed permission to use data from the two instruments and survey in this report. Under no circumstances were individual reports shared with other students.

\section{Results}

\subsection{Correlation Studies}

The EP10 was scored on a ten-point scale, whereas the EMP was scored on a five-point scale. In order to compare the two scores, the EP10 data was converted to a five-point scale as shown in Table 6.

Table 6: Mapping of EP10 data to a five-point equivalent scale

\begin{tabular}{cc}
\hline \hline EP10 Score & Five Point Scale \\
\hline 1 and 2 & 1 \\
3 and 4 & 2 \\
5 and 6 & 3 \\
7 and 8 & 4 \\
9 and 10 & 5 \\
\hline \hline
\end{tabular}

Next, we constructed scatterplots and calculated Spearman's correlation coefficients of students' five-point EP10 scores versus their EMP scores, Figure 2.

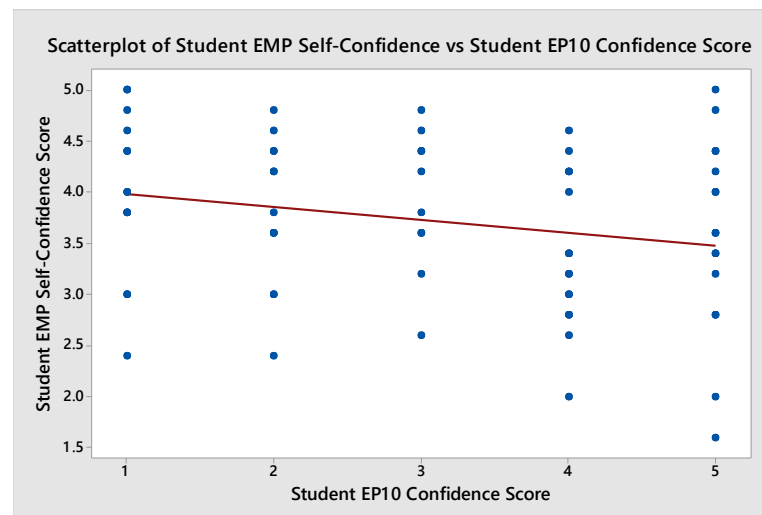

(a)

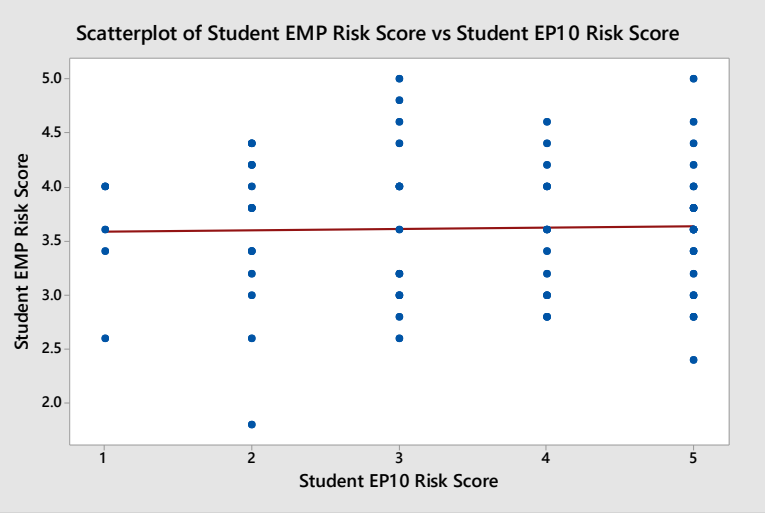

(b) 


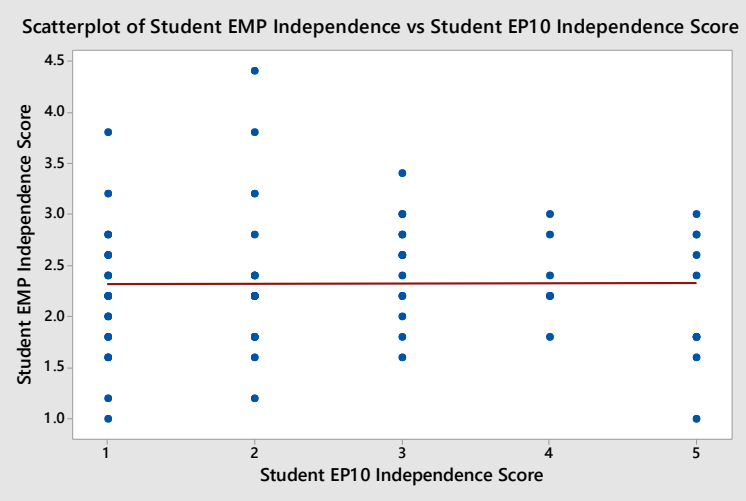

(c)

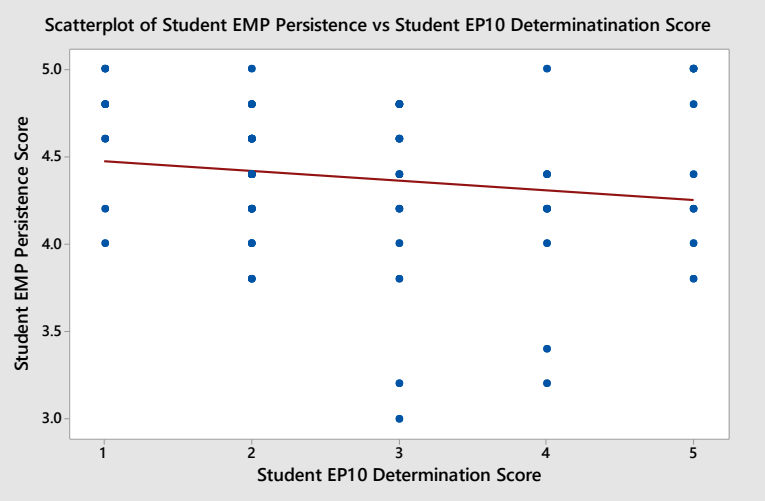

(d)

Figure 2: Scatter plots of EP10 versus EMP scores: (a) Confidence vs. Self-Confidence, (b) Risk vs. Risk Acceptance, (c) Independence vs. Independence, and (d) Determination vs. Persistence

The Spearman correlation coefficient $\rho$ is used to measure the strength and direction of association between the ordinal EMP and EP10 variables. The null and alternative hypotheses associated with $\rho$ are:

$\mathrm{H}_{0}: \rho=0$; i.e., there is no correlation between the two variables

$$
H_{a}: \rho \neq 0 \text {; i.e., there is a correlation between the two variables. }
$$

A test resulting in a small $p$-value (typically, less than 0.05 ) suggests that there is a correlation between the two variables. The correlation coefficients and their corresponding $p$-values are shown in Table 7.

Table 7: Spearman's correlation coefficient $\rho$ and $p$-value for the four EMP/EP10 categories

\begin{tabular}{ccc}
\hline $\begin{array}{c}\text { EP10/EMP Equivalent } \\
\text { Categories }\end{array}$ & $\begin{array}{c}\text { Spearman's Correlation } \\
\text { Coefficient, } \boldsymbol{\rho}\end{array}$ & Corresponding $\boldsymbol{p}$-value \\
\hline Confidence / Self-Confidence & -0.220 & 0.072 \\
Risk / Risk Acceptance & 0.026 & 0.835 \\
Independence / Independence & 0.003 & 0.979 \\
Determination / Persistence & -0.115 & 0.208 \\
\hline
\end{tabular}

The data in Table 7 suggests that the equivalent EMP/EP10 categories are not correlated, except with a moderate negative association between "Confidence" and "Self-Confidence." This is not an intuitive result. Our expectation was that if both instruments were using the same category descriptors, such as Risk, Independence, etc. that students would have a reasonably consistent category score on both instruments. 
The lack of correlation may be explained by the format of the individual items that determine a category score, for within these items the two assessment instruments took very different approaches. For example, the EMP uses a Likert-type scale, while the EP10 does not. Consider here an example of an EMP item related to the assessment of Risk and the corresponding scoring:

$$
\begin{aligned}
& \text { Does not describe me well } \\
& \qquad \begin{array}{llllllll}
1 & 2 & 3 & 4 & 5 & \text { Describes me well } \\
\text { l am willing to take some risks if the payoff is big enough. }
\end{array}
\end{aligned}
$$

The EP10 uses a different item format. Here is an example of an EP10 item related to Risk:

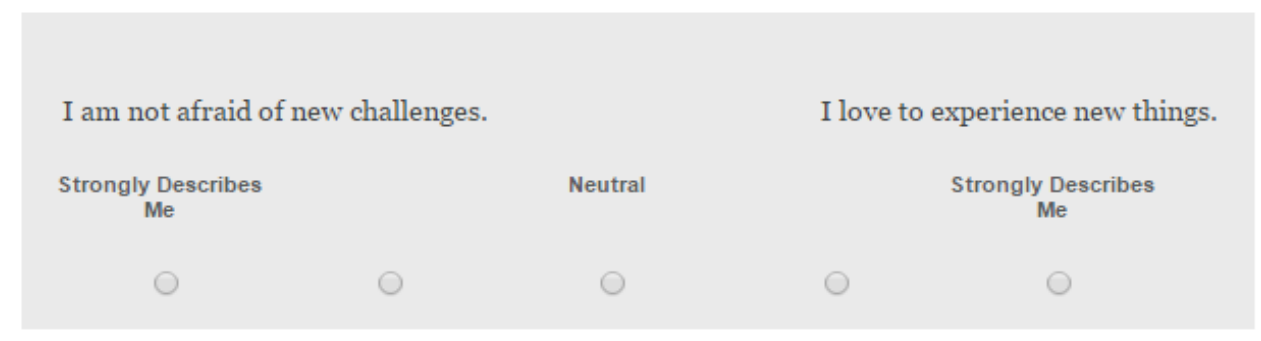

The EP10 requires the applicant to make an association choice between two statements, whereas the EMP provides only one statement and the applicant chooses how well they identify with that statement. It appears that these differences at item level, including both the text of the descriptors and the scoring method, have a significant impact on the results. The two instruments may not be measuring the same personality traits/skills; even though the four category descriptors researched here appear synonymous.

\subsection{Student Preferences}

After completing the EMP and EP10 online and discussing in class how to interpret their individual results, 65 of the 70 students participated in a reflection exercise where they completed a post-instrument survey. The anonymous follow-on survey sought to gain an understanding on three items:

(i) to determine whether or not the psychometric surveys provided students with useful insight on their entrepreneurial tendencies (required response was either Yes or No),

(ii) to assess which survey offered the best design and presentation of results (required response was either EMP or EP10), and finally,

(iii) to determine which of the two surveys provided the best apparent cost/benefit ratio (required response was either EMP or EP10).

The results from item (i) indicated, overwhelmingly, that students felt both instruments provided valuable insight on their entrepreneurial tendencies. Only two students $(\sim 3 \%)$ felt the 
information was not useful. Knowing that $97 \%$ of students gained something useful from the assessments and resulting discussion in class, the authors feel there is an academic value to administering these instruments.

In an our effort to minimize survey fatigue, to reduce cost, and to streamline the process, we were also interested to know if there was a strong preference for either the EMP or EP10. Ideally, going forward, the authors would like to use only one instrument when assessing the entrepreneurial-mindedness of our students. As such, the authors hoped responses to items (ii) and (iii) would provide an indication of student preference.

When assessing student preference for format of survey questions and presentation of results, a majority choice was not apparent, with only slightly more students (54\%) selecting the EP10 over the EMP. Additionally, the EP10 earned a slight advantage (52\%) when students were asked to make an economic judgment. Meaning, if they could only afford one of the two online instruments, which one would they select to gain the most insight into their entrepreneurial self. Recall, student cost for the EP10 (\$12) is approximately half the cost of the EMP (\$25). However, for an unbiased response, students did not pay for either instrument and the actual cost was never disclosed. An email link or access code was used to initiate the instrument.

A final point of interest was that five students (8\%) did not choose the same instrument when responding to items (ii) and (iii), meaning that while the format of one instrument may have been preferred over the other, when it came time to make a mutually exclusive financial decision, they choose the other instrument. As the authors continue to expand the number of students participating in this study, we may seek more clarity on this dichotomy.

\section{Conclusion}

The Entrepreneurial Mindset Profile (EMP) by Eckerd College and the Entrepreneurial Profile 10 Index (EP10) by Gallup have many attributes in common, but there are significant differences in the formatting of items and in the presentation of results.

From a student's perspective, survey results overwhelmingly support the value of the instruments in providing some insight into their entrepreneurial tendencies. However, students were almost equally split on which instrument they preferred from the perspective of both format and cost/benefit ratio.

While both instruments use the same or synonymous words to describe personality traits/skills, there was no statistically significant correlation between student responses across the four categories examined. We conclude that differences in item text and related scoring methods do not support our hypothesis that students taking one instrument will score in a similar manner on the other instrument, even though the category descriptors may appear to be the same. 


\section{References}

1. Audretsch, D. B., 2007, The Entrepreneurial Society. New York, NY: Oxford University Press.

2. Pryor, J. H. and Reedy, E. J., 2009, “Trends in Business Interest Among U.S. College Students: An Early Exploration of Data Available from the Cooperative Institutional Research Program," Ewing Marion Kauffman Foundation.

3. Yang, A., 2014, Smart People Should Build Things. New York, NY: HarperCollins Publishers.

4. Boyd, N. G. and Vozikis, G. S., 1994, "The Influence of Self-Efficacy on the Development of Entrepreneurial Intentions and Actions," Entrepreneurship Theory and Practice, pp. 63-77.

5. McGrath, R. G., 2000, The Entrepreneurial Mindset: Strategies for Continuously Creating Opportunity in an Age of Uncertainty. Boston, MA: Harvard Business School Press.

6. Condoor, S. and McQuilling, M., 2009, "Incorporating an Entrepreneurial Mindset in Freshman Engineering Students," ASEE Paper AC 2009-1825.

7. Fry, C. C., 2011, "Assessing the Entrepreneurial Mindset with Engineering Programs," ASEE Paper AC 2011-2417.

8. Bilan, S. G., Kisenwether, E. C., Rzasa, S. E., and Wise, J. C., 2005, "Developing and Assessing Student's Entrepreneurial Skills and Mindset," Journal of Engineering Education, Vol. 94(2), pp. 233-243.

9. Meyers-Briggs Company at https://www.cpp.com.

10. Davis, M. H., Hall J. A., and Mayer, P. S., 2016, "Developing a New Measure of Entrepreneurial Mindset: Reliability, Validity, and Implications for Practitioners," Consulting Psychology Journal: Practice and Research, Vol 68(1), pp. 21-48.

11. Badal S. B. and Streur J. H., 2014, Gallup Entrepreneurial Profile 10® Methodology Report at https://www.gallupstrengthscenter.com. 